Arch Virol (1989) 104: 335-337

Airchives

\title{
The use of nucleic acid hybridization to detect human coronaviruses
}

\author{
Brief Report \\ S. Myint ${ }^{1}$, S. Siddell ${ }^{1}$, and D. Tyrrell ${ }^{2}$ \\ ${ }^{1}$ Institut for Virology, University of Würzburg, Würzburg, Federal Republic of Germany \\ ${ }^{2}$ MRC Common Cold Unit, Salisbury, England
}

Accepted January 6, 1989

Summary. We have applied an RNA : RNA hybridization test for the detection of human coronavirus $229 \mathrm{E}$. This test is undergoing further development but already allows a diagnosis of HCV 229E infection within 48 hours.

Human coronaviruses are positive-strand RNA viruses that are thought to cause about $20 \%$ of all common colds. They have also been associated with other diseases [1] but only the association with respiratory tract infection is substantiated [2]. Coronaviruses have an unusual replication strategy which involves a $3^{\prime}$ coterminal set of subgenomic mRNAs. Only the $5^{\prime}$ proximal region of each mRNA generally codes for a protein. In the case of human coronaviruses the smallest of these subgenomic mRNAs codes for the nucleocapsid protein. We have used an oligo-dT primer and a method based on that of Gubler and Hofmann [3] to create a library of human coronavirus (HCV) 229E cDNA clones. From this library, cDNA representing a complete copy of the nucleocapsid gene has been identified and subcloned into the 'riboprobe' vector pGEM-1. This vector has a promoter site for the attachment of T7 RNA polymerase, using which ${ }^{32} \mathrm{P}$-labelled single stranded RNA transcipts can be generated. These transcipts have been shown to be more sensitive than nicktranslated double-stranded DNA probes in the detection of HCV 229E RNA [Myint et al., in prep.]. Their specificity has been examined by hybridization to a series of filters onto which had been bound RNA from 42 common cold pathogens (HCV 229E, HCV OC43, HCV 229E/Killick, 4 parainfuenza, 4 influenza and 31 rhinoviruses), only the HCV 229E group were detected (unpublished data).

This "riboprobe" has now been successfully applied to the detection of HCV 229E in nasal washings collected from volunteers infected with the virus 


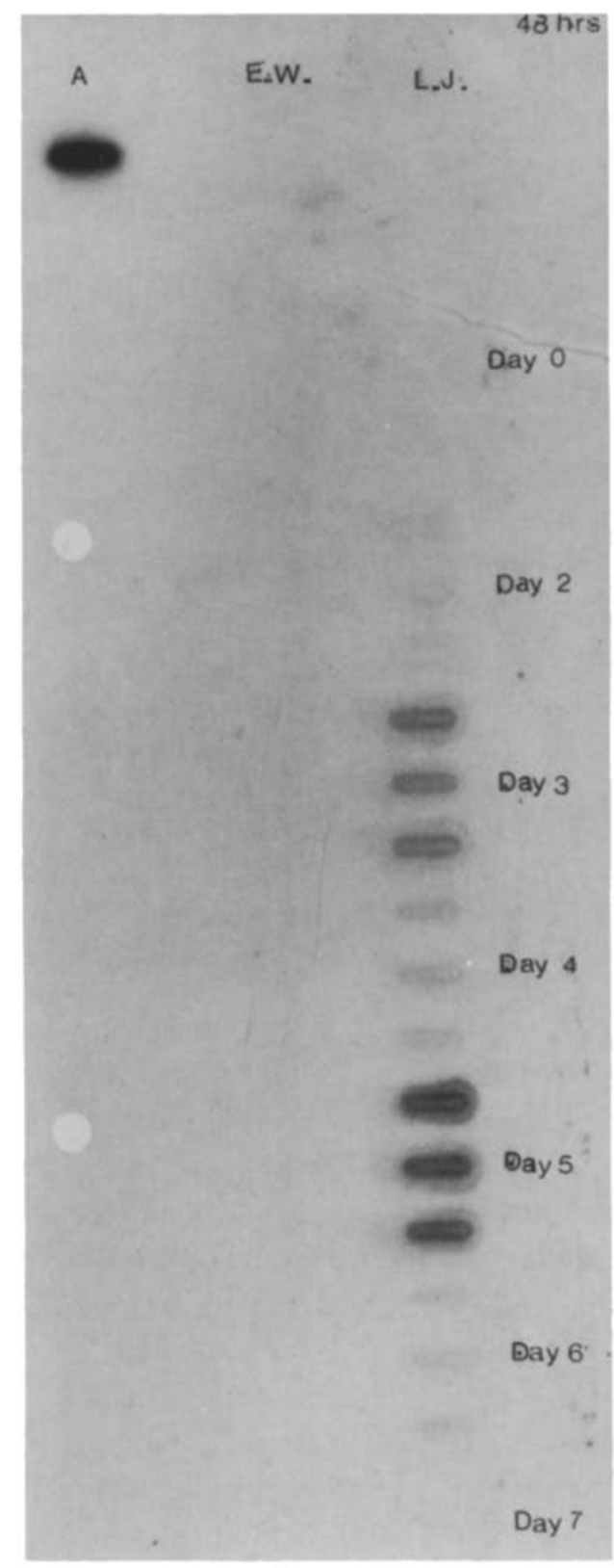

Fig. 1. Hybridization of ${ }^{32} \mathrm{P}$-labelled RNA probe to nasal washings from $\mathrm{HCV} 229 \mathrm{E}$ inoculated volunteers. (See text for details)

in a controlled trial. Of eight volunteers inoculated intra-nasally with HCV $229 \mathrm{E}$ four suffered a cold. Nasal washings from these four had detectable HCV 229E RNA. Nasal washings from the asymptomatic volunteers did not have detectable viral RNA. It is important for reliable detection that the nasal washings are collected with an RNAse inhibitor, we have used $20 \mathrm{mM}$ vanadyl-ribonucleoside complex (VRC). $100 \mu \mathrm{l}$ nasal washings are then treated with proteinase $\mathrm{K}(2 \mathrm{mg}$ / 
$\mathrm{ml}$ working concentration), and applied with the addition of an equal volume of $6.15 \mathrm{M}$ formaldehyde $/ 10 \times \mathrm{SSC}$ to a nitrocellulose filter using a Schleicher $\&$ Schuell slot-blotting manifold. After baking, their filter is then probed by a ${ }^{32} \mathrm{P}$-labelled single-stranded RNA probe: using the protocol of Melton et al. [4] probes with a specific activity of $10^{9} \mathrm{cpm} / \mu \mathrm{g}$ are generated. Figure 1 shows a photograph of an autoradiograph of an RNA : RNA hybridization of nasal washings that have been collected on 7 days from an individual who developed a cold (L. J.) and an individual inoculated with virus but who did not suffer a cold (E.W.), day 1 being the day of virus inoculation; each sample has been applied in triplicate. Track A has poly A + RNA from HCV 229E infected C 16 cell RNA as a positive control and non infected C16 cell RNA as a negative control. The method currently requires at least 24 hours autoradiography to produce a result but this compares with 8 to 10 days by virus isolation in monolayer cell culture. The method is currently being modified and will be further evaluated. We feel that this test will prove to be a useful epidemiological tool, and will replace virus isolation as a means of HCV 229E detection for several reasons: it is relatively rapid, it requires little expertise to perform, multiple samples can be examined quickly, and, unlike cell culture, it can detect both drug and antibody bound virus.

\section{Acknowledgements}

This work is supported by a grant from the European Commission. All volunteer studies are subject to ethical approval by the Northwick Park Hospital ethical committee.

\section{References}

1. Riski H, Hovi T (1980) Coronavirus infections of man associated with diseases other than the common cold. J Med Virol 6: 259-265

2. Isaacs D, Flowers D, Clarke JR, Valman HB, MacNaughton MR (1983) Epidemiology of coronavirus respiratory infections. Arch Dis Child 58: 500-503

3. Gubler U, Hofmann BJ (1983) A simple and very efficient method for generating cDNA libraries. Gene 25: 263-269

4. Melton DA, Krieg PA, Rebagliati MR, Maniatis T, Zinn K, Green MR (1984) Efficient in-vitro synthesis of biologically active RNA and RNA hybridization probes from plasmid containing a bacteriophage T7 promoter. Nucleic Acids Res 12: 7035-7056

Authors' address: Dr. S. Myint, MRC Common Cold Unit, Coombe Road, Salisbury SP2 8BW, England. 